This item was submitted to Loughborough's Research Repository by the author.

Items in Figshare are protected by copyright, with all rights reserved, unless otherwise indicated.

\title{
Edge, common space and the spatial contract: A three-way conversation with Ed Casey, Stavros Stavrides and Antonis Vradis
}

PLEASE CITE THE PUBLISHED VERSION

https://doi.org/10.1016/j.polgeo.2018.08.005

PUBLISHER

(C) Elsevier

VERSION

AM (Accepted Manuscript)

\section{PUBLISHER STATEMENT}

This paper was accepted for publication in the journal Political Geography and the definitive published version is available at https://doi.org/10.1016/j.polgeo.2018.08.005

\section{LICENCE}

CC BY-NC-ND 4.0

\section{REPOSITORY RECORD}

Casey, Edward S., Stavros Stavrides, and Antonis Vradis. 2018. "Edge, Common Space and the Spatial Contract: A Three-way Conversation with Ed Casey, Stavros Stavrides and Antonis Vradis”. figshare. https://hdl.handle.net/2134/35043. 


\section{Undrawing the line: a three-way conversation with Ed Casey, Stavros Stavrides and Antonis Vradis}

From an innermost feeling to a passionate political declaration, we "draw the line" at that particular moment or place determining what we deem acceptable. We seem to carry, in other words, some strict-if-figurative marks in our minds: cognitive lines that determine what we do or do not accept; lines that come to greatly shape our collective way of being. There is always a line (whether in time or in space) that signals when and where is really enough for each of us.

For a brief historical moment, in the soothing numbness of post-WWII welfare capitalism, those lines vanished out of sight. In that brief moment, those of us privileged enough to exist in the Global West largely fell for the illusion that there might, after all, be enough to go around for most of us. The illusion that personal prosperity didn't necessarily have to come at the expense of a dire livelihood for others-not, at least, those in our immediate vicinity.

Our current historical moment is doing away with these naivities. In a world swiftly broken into a myriad compartments, illuminating such invisible-or very visible-lines, cognitive or tangible, has now emerged, I would think, as one of the most important political tasks of our time. From the chilling blasts from the past, such as metallic fences separating children from their parents all the way to oh-so-contemporary, perniciously reverberating digital walls of our individual echo chambers, we have been ushered into an era when lines are drawn in neckbreaking speed, ramshacking livelihoods and reshaping the very essence of what it means to be human along the way.

This is why it is vital to both highlight these processes, and to dispel two commonly encountered myths surrounding them. One, the myth that our world is threatened by naturally occurring "emergencies" that call for tolerating, if not outright justifying, drawing these lines. And two, the myth that said lines are drawn without any formidable resistance: that the fragmentation and compartmentalisation of people's lives the world over isn't met and countered by other attempts, driven by opposed and alternative visions for our present and for our future.

Strange and crucial times call for doing things a little bit differently. With this in mind, what follows in the next few pages is not quite like your conventional book review. The idea came briefly after the publication of Ed Casey's The World on Edge (Bloomington: Indiana University Press, 2017) and Stavros Stavrides' Common Space: the City as Commons (London: Zed Books, 2016). Kindly responding to an invitation to review each other's work, Ed and Stavros have provided us with a fantastic glimpse into each other's writing-and the force driving their own.

As you will see, the parallels are striking: here are two thinkers physically separated by thousands of miles, arriving from different scholarly traditions, and still grappling questions that allow a direct, unhindered dialogue. It is not a coincidence, I would argue, that this convergence comes at the present historical moment. A moment when more and more of us wake up to the realisation that the drawing of lines around us is catastrophic, that complacency is not an option, that we must draw the line precisely at the urgent need to undraw these lethal lines.

Antonis Vradis, Athens, summer 2018 


\section{Ed Casey on Stavros Stavrides' Common Space: The City as Commons}

Common Space: The City as Commons is anything but common. It is an exceptionally thoughtful study of the process and procedures of commoning, investigating the major ways by which common spaces are created in the contemporary world. Its major concern is to trace out what the author calls "expanding commoning" in contrast with all the enclosures or "enclaves" that reflect, directly or otherwise, capitalist domination on earth today. The expansiveness of communities has everything to do with the continual creation, and frequent re-creation, of spaces that contribute to the well-being of those who inhabit them. It calls upon a special resourcefulness that is shared by those who co-participate in such spaces-not merely navigating them, but actively modifying and transforming them in the interest of equality and justice. It is a matter of the co-creation of an authentic "commonwealth," where this term refers to something more essentially social and political than economic. In short, Common Space lays out a blueprint for bringing about desperately needed changes to the body politic in its current state of hierarchical organization and social sclerosis.

In this brief review, it is difficult to do justice to a book that takes up so many aspects of creative commoning, drawing on all the most relevant sources from Foucault to Rancière, from Benjamin to Sennett, including a series of related studies by Stavrides himself. Accordingly, I shall limit myself to a condensed account of certain major concepts and issues, followed by a short series of lacunae I find in an otherwise remarkable and immensely rewarding text.

Enclaves are constrictive modes of spatial organization such as are found in gated communities as well as in fenced parks, prison complexes, and detention centers. In such places, movement is regulated by the concerns of those in control-those with the police power to predetermine and overdetermine the nature of shared space. Enclaves are organized by "specific protocols of use" (18) that are not subject to discussion, much less revision. They are "normalized enclosures" (in Soja's term) that are in effect localized "states of exception" (Agamben). Depending on the historical era and exact circumstances, they put into practice the preoccupations of sovereign, disciplinary, and security-minded modes of power (in keeping with Foucault's tripartite analysis). Faced with the proliferation of enclaves in today's world-spaces that exhibit control from above and without, and that curtail the free movements of those who are forced to live in accordance with these modes-Stavrides poses the critical question: how are we today not just to imagine but to realize alternative shared spaces in which resistance gives rise to mutually affirmative co-existence in a world overwhelmed by global capitalism? Refusing simplistic solutions, he argues eloquently and persuasively for a multiplex set of solutions, each pitched in socially explicit spatial terms.

The major issue is how to transform "common worlds"-defined as "worlds with recognizable boundaries" (31)_into expansive spaces not just of equal treatment and opportunity but of communal innovation and collective self-direction. Such spaces encourage and engender "active participation in the shaping of the rules that sustain them" (32). This participation does not aim at creating consistent or homogeneous social spaces but rather "worlds of commoning" in which diversity of direction is not only tolerated but itself becomes a major motor of change. It is axiomatic for Stavrides that "commoning unfolds in all levels of social life" (35), a process in which "different groups or individuals... become co-producers of a world-in-the-making" (50). These groups are not just those constituted by class differences but by race, gender, differential history, etc., but by human beings who have differential senses of how to reshape common spaces to the benefit of all who inhabit them, especially in the urban contexts that are the primary concern of Stavrides, who is both an active (and activist) architect of urban spaces and a visionary with regard to an ameliorated future of these same spaces. 
Stravides usefully distinguishes between three ways by which city dwellers, very much including those living on the margins of cities, can conjoin constructively so as to amplify what is otherwise only a literal convergence of experiences: there has to be an effort to establish comparability between different sectors of common worlds; an effort at translating between these sectors with an "inherent inventiveness" (43) and that welcomes newcomers (thus a matter of hospitality: a theme that remains largely tacit in the text); and power-sharing in an "always-expanding network of self-governance institutions" (44) ${ }^{1}$. Leading examples of the successful pursuit of all three goals, especially the third, are found in various forms of the Occupy movement and especially in the Zapatista "autonomous" communities in Chiapas.

Stravides emphasizes that expansive commoning is not just a matter of pursuing the most promising literal collective practices but of the formation of new "collective subjects of commoning" (49). This last theme is important and promising, and it raises the question: what is a "collective subject"? There is no easy answer to this last question, which raises an issue first posed by earlier writers such as Durkheim (in his idea of "collective effervescence") and Halbwachs (in his analysis of "collective memory") ${ }^{2}$. Stavrides offers an important clue of his own when he adds that political subjectivation "can be considered as a process which moves not towards the construction of collective identities and social bodies but towards new forms of coordination and interaction based on commoning practices which create open communities of commoners." (177) One can still ask, however, how "coordination and interaction"-modes of overt conduct that are at once social and spatial-relate to the interiority of political subjects: where, who, is the subject in subjectivation? What is the role of the psychical dimension of such subjects? A hint is given on the last page of the book, when there is a brief allusion to "subjects of sharing" who "can be transformed through sharing and [thus] subjects who recognize in sharing the power of opening to potential worlds..." (272) What, then, is the process of transformation of such subjects? Without an account of their metamorphosis from within, the very subjects who are to effect change lack any coherent sense of self with and by which common worlds-in-the-making are brought about in conjoint action with others.

This brings us to the rich meditation on thresholds that is the theoretical heart of this book and perhaps its most signal contribution to spatial studies. The initial term "boundaries" that delimit common spaces is left deliberately undefined, as in the early statement that "common worlds tend to be defined and reproduced as worlds with recognizable boundaries" (31). Despite their inherent vagueness, boundaries nevertheless serve to set off one common space from another. They are what makes such a space "porous" $(54,65)$. Here I would add that boundaries are usefully contrasted with borders, which are essentially impermeable and are characterized by their rigidity, as in the case of border walls and the walls of prison cells ${ }^{3}$. It is only when a boundary becomes a "border" that the porosity ceases. Thresholds are yet a third thing: permeable as they are, they are not mere delimiting factors; they are more than mere boundaries, which are always indifferently two-way in their inherent directionality, going in or going out. In contrast, thresholds are what give access to another space or another level of activity in the same space. They do more than demarcate inside from outside, as with boundaries and borders alike; they are transitional spaces that solicit active movement across them-after which one finds oneself in another space.

1 "Gift offering" is a fourth mode mentioned but not pursued by Stravides: see pp. 48-49.

$2 \quad$ Stavrides takes up collective memory in ch. 7.

3 Stravides considers borders to be porous: see p. 69 for a discussion of "porous

borders." For the distinction between borders and boundaries, see The World on Edge

(Bloomington: Indiana University Press, 2017), chapter one. 
I borrow the term "transitional" from D.W. Winnicott, who posited "transitional spaces" as the in-between areas in which important changes occur for those who pass through them: indeed, that may alter their very identity ${ }^{4}$. Such spaces do not merely demarcate the edges of a given common site; they offer the very passage out of one such space (typically more constricted: as in the case of an enclave) into another (typically more expansive and lifealtering). In other words, transitional spaces deconstruct the very idea of a fixed position and introduce the dynamic idea of passage. If for Winnicott, the passage is from a more habitual to a more "playful" way of being in the world, for Stavrides it is from being confined to a pre-existing enclosure to a more actively participatory way of being in a common space thanks to becoming more fully part of co-ordinated movements of "expanding commoning."

A threshold, then, is not merely a limit, nor even an intermediate area of contact but a dynamic zone in which social change happens. It is the equivalent in secular culture of the rites de passage that characterize initiation rites in many indigenous cultures-for example, among the Mayans in certain Guatemalan villages ${ }^{5}$. But it differs from the latter in its insistence on finding new styles of self-governance that are radically democratic, typified in the General Assemblies in Occupy or in the local town councils in autonomous Zapatista communities. Only people who are willing to go to the outer edges of what they already know and have experienced up to then can achieve genuine liberation from the constrictions of enclosed spaces-thus from the normalizing rules, explicit as well as tacit, which they come to realize are holding them back and holding them down.

Stavros Stavrides' ultimate aim is to discern the practices that lead to emancipation within urban settings. To do justice to the most efficacious of these practices, he has to walk a fine line between the model of open space-enough space for collaboration as well as experimentation-while respecting the need for delimitation and definition of that same space. Such a space is precisely a threshold, which serves to define what, late in the book, Stavrides terms "the "spatiality of emancipation" (239). This spatiality consists in "in-between spaces" that do not pre-exist their traversal but are created by the traversals themselves-whether actual or virtual-and that amount to "crossroads" that connect "separated potential destinations" (239). Seen in this light, thresholds take the place of fixed and intensely policed checkpoints such as are found at international borders; instead of being restricted to an either/or option ("Enter" vs. "Do Not Enter," depending on what documents must be shown for access), thresholds provide pathways to differential and open futures ("You May Go This Way"-or "Try That Way," or "Consider This Other Way"). This is not just the case for individuals but for whole groups of people who are bonded by their ever-expanding commoning. The result is a collaborative solidarity not otherwise possible. In short, thresholds "provide the ground for a possible solidarity between different people [who are] allowed to regain control over their lives." (240).

Common Space is a book replete with insight into the primary vectors as well as the nuanced structures at stake in creative commoning. It is an eloquent and forceful statement that fills a major void in the literature on liberatory activity in the life of urban spaces. Stavrides has firstperson knowledge of many of the events that count as the most effective forms of commoning to date, and he gives vivid accounts of them. This becomes especially evident in the chapters that succeed the treatment of threshold. These chapters take up such concrete matters as city

$4 \quad$ See D. W. Winnicott, Playing and Reality (New York: Routledge, 1971), esp. chapter one, "Transitional Objects and Transitional Phenomena."

$5 \quad$ Concerning such initiation rites among the Mayan, see Martin Prechtel, Long Life, Honey in the Heart: A Story of Initiation and Eloquences from the Shores of a Mayan Lake (Berkeley: North Atlantic, 1999), esp. chapters two, three, and four. 
streets considered as "contested spaces"-that is, spaces where effective protests are very likely to occur. Another chapter takes up housing issues that bear on the creation of commons-issues of homelessness, of the formation of favelas and bidonvilles located at the outer edges of established cities that offer fertile ground for transformative commoning. Still another chapter discusses occupancy situations (especially those in which urban parks and squares are selected as locations for protest); in these, disfavored people join forces, often in public squares, and there devise possibilities of self-governance, several of which Stravides discusses in detail and with nuanced insightfulness.

Stravides' concerted focus on the specifically social dynamics of shared emancipatory practices - their sheerly intersubjective dimensions-is such that certain aspects of these same practices do not come into consideration. These are not flaws as such but rather areas l'd like to have heard more about. In Aristotelian nomenclature, they are defects of the very virtues of his enterprise. Let me single out four of these for brief comment. (a) Earlier, I pointed to the character of the kind of political subjectivity that is at stake in these practices; the phrase "political subjectivation" is employed a number of times by the author, yet is not pursued to the point where the reader learns what this consists in concretely. "Subjectivation" surely entails the creation of human subjects, and such subjects are always singular; but what renders them singular in the formation of common spaces is not proffered. (b) Another area of comparative neglect concerns the ingredience of place in human experience. It is only rarely mentioned in the book (e.g., 26, 31, 240), yet in my view it is pivotal in the creation of common spaces of many kinds. The paucity of its invocation may reflect the view that place is too static for the author's purposes. But what is static is site, not place. On my view, place is animated and is itself animating. It has a dynamic aspect that allows us to regard it as eventmental, as is suggested in the term "placement." Thus it cannot be considered a form of enclave (given the comparatively fixed nature of the latter); it is also not equivalent to a threshold, which is a dimension of place in its active aspect. It is telling in this context that what Stavrides says about "common space" I would say precisely about place: "space matters because it is not an inert container of social life but an integral part of its manifestation and its events" (260). Further, the author's important distinction between common, public, and private space (261 and earlier) can be said to characterize three cardinal forms of place. Moreover, when it is claimed that "common space... cannot be reduced to a place, although acts of commoning unfold in specific places and times, indeed take place" (262), I would certainly agree: space, regarded as a skein of places, cannot be reduced to any single paradigmatic place; the places that make up social space are dynamic factors that are more events than things ("take place" connotes 'event'). (c) The role of bodies in the praxis of urban commoning is rarely mentioned in the book here under review; yet it is surely by bodily agency that the very activities so deftly delineated by Stavrides can arise in the first place. I am not here calling for the kind of close-up descriptive account that Merleau-Ponty or Nancy might offer, but rather for a description of just how bodies operate in the crossroads and at the thresholds singled out as paradigmatic by Stavrides (e.g., in his lively account of the occupation of Navarinou Park in 2009 in Athens, as presented in the last chapter of Common Space). (d) Stavrides considers otherness to be essential to a vibrant common space (70); it is both essential to it and, far from being a threat, it is a "promise" (71). This is an intriguing line of thought; but it is not made clear in what this otherness consists: is it a matter of empirical differences of race, country of origin, gender, etc., or is it (as Levinas would insist) more of a metaphysical dimension of all human others, who inspire ethical behavior on our part when we recognize their destitution and respond to it with care and concern? The level and kind of otherness at stake in spatial commoning calls for further specification. A clue is offered in the claim that heterotopias "make otherness visible" (75); but just what kind of otherness is here conveyed?

Of course, one cannot cover all aspects of a circumstance as polymorphic and multidimensional as the challenge of expanded commoning entails. What matters is what this 
singular book does accomplish, and this is something truly exceptional. Every page is filled with invaluable insights and observations. The text as a whole strikes a fine balance between spatial studies, political theory, and emancipatory practices. The references to actual circumstances are apt and telling; they anchor the stretches of theoretical considerations that are themselves notable for being creative extensions of the pioneering work of Agamben, Foucault, and Rancière. Yet Stavrides is by no means beholden to these and other predecessors. He thinks through the concrete requirements and specificities of commoning activity. At every turn, he comes up with fresh formulations of what happens when expansive commoning is achieved. The result is a superb contribution to our understanding of how we can find meaningful alternatives to the striated spaces that beleaguer the contemporary world of unbridled capitalism. Common Space allows us to understand better the dark dynamics of this world while offering a vision of how more auspicious worlds-in-the-making can emerge in times to come. 


\section{Stavros Stavrides on Ed Casey's The World on Edge}

As if summarizing both the content and the method of his book, The World on Edge, Ed Casey states that he is concerned "with any kind or level of experience, implicit of explicit, in which edges are operative, including those that belong to transhuman realms, as in wilderness or the sky" (300). Explicitly, then, this is not merely a book based on a descriptive typology of edges but a book about the ways in which edges become operative in human experiences. Constructing a method he terms peri-phenomenology, Casey distances himself both from a purely ontological approach (in search for edge 'essences') and a purely descriptive one based on a naive empiricism. Boldly affirming the existence of edges as "presences", he distinguishes himself both from subjective idealism ("as if by looking at or touching them we bring [edges] into-being", 19) and from a materialism that clearly separates objects from subjects and therefore the "objective" description from any "subjective" one. In exploring edges as presences this book supports so; but it is developed in a way that convinces us that edges explicitly matter in the everyday human dramas and aspirations. Faithful to an American tradition of using accessible language to discuss complicated issues, Casey explores edges in an effort to expand our awareness about the world that we live in and about the potentialities which emerge in our being part of this world (which is actually many worlds and one world at the same time). Take for example the discussion about a crucial distinction which permeates the book: the border as distinct from the boundary. Both are edges, however the border is more like a definable and defining edge whereas the boundary is necessarily porous, and less clearly defined. "Borders are artifacts... whereas boundaries emerge from what is already given..." (16). And as the book unfolds, boundaries are being presented as edges which engender exchanges, as forms of closure that enhance becoming rather than being.

Indeed, Casey asserts that edges are of many kinds (of "distinctive species" - 299) but he clearly shows how hard edges can be truly suppressive, as in the case of the US border wall that blocks immigrant trajectories, whereas flexibility may encourage encounters and, thus, promote "interfusion" (126). Interfusion is however also the condition under which artificial (human made) and natural edges interact. Refusing to accept a primary distinction between nature and culture-and he is right when it comes to the complexities of experiences-Casey believes in a "dynamic commixture" which creates a "radical interfusion of artifactual and natural edges" (127).

The rich typology of edge presences (or edge experiences) which is being developed in this book can be a major source of inspiration for potential researches concerning geography and spatial theory. Even if someone seriously questions the transcultural presuppositions of such typology (basically constructed in Part I), there is no doubt that the heuristic value of the terms analyzed (folds, creases, margins, verges, rims, thresholds, frames, gaps, cusps, traces) is great. What seems to be however more important is the discussion about space (as distinct from place) that is being developed in the book according to the edge-presencing logic.

We know from his work on the Fate of Place that Casey clearly favors places over abstract space. In stark contrast to space which can have only limits (that are always bound to totalities) places have edges (53). And "edges of places are more like boundaries than borders" (78). This means that places are edge worlds in which multiple interactions may unfold. And more than that, in places edges interact with edges (76). This is how we can understand the edges of a neighborhood, of a street, or even of a landscape.

Furthermore, what place is compared to space, event is compared to time. Events also have edges and it is because of this that time is experienced neither as homogeneous nor as monolithic (83). Taken in their co-presence, places and events actually shape through the interaction of their edges a series of beginnings and endings as well as a multiplicity of durations. 
This is a powerful suggestion on the possible treatment and interpretation of lived spaces. We need to observe the ways edges interact if we are to create and sustain lived worlds which are not to be reduced to exclusionary and exclusive enclaves. Observing the ways edges interact in cities, we may learn how to enhance porosity, and how to activate different opportunities of exchanges (marked by event edges, or, perhaps, by rhythmicalities in Lefebvre's terminology). We need to visualize the future of society as well as the future of cities as possessing edges that will be "boundary-like" and "threshold-traversing" (352). And we may even valorize the aspect of surprise that both event and place carry with them by being distinct from the imposed abstract order of time and space respectively, as Casey suggests (55).

What we possibly miss from Casey's humanistic approach (very much needed in times of prevailing cynicism) is the grounding of this innovative knowledge concerning edges on the historicity of social interactions. There is much to learn from the way, for example, artificial and natural edges are being understood and experienced in different (albeit contemporary) cultural contexts. We know how predominant is a scheme of philosophical reasoning according to which the writer may take his or her experiences (or sentiments, or thinking processes) as indicative of the "human" in general. Faithful to this tradition, Casey very often supports his arguments by giving examples from his personal experiences. And this may be sometimes quite clarifying and even indicative of a man with heightened capacities of observation as well as with a rich ethical reasoning.

Clearly Casey is not a distantiated 'entomologist' studying human behavior. His research is part of an implicit effort to explore a better life with respect to nature and to the different ways of being human. And he clearly and dramatically warns us about our world being on edge since a "systemic edge" (a term of Sassen's - 347) marks a period of destructive phenomena (predatory economic practices, climate crisis, the fate of expulsion for many, war-forced immigrations). However, we need the cross-fertilizing interactions of philosophy with anthropology and history if we intend to explore phenomena that may change the ways we live in this world.

Casey's approach, thus, would surely gain from comparisons between different contexts of individual and collective experiences which may indeed support the view that edges matter in social relations. Do pilots and sailors, nomads and immigrants share the same experiences when gazing at the horizon edge? Could we learn something from their different approaches? Could we deduce a common ground for their instances or is there an inherent multiplicity that attributes to edges a context-specific role in social life?

One more opportunity to intersect this book's findings with research focused on the social may be found in the very slippery and difficult ground of "psychical edges". True, by making reference to Freud, Klein Winnicot and others Casey tries to integrate his thoughts to current psychoanalytic discussions. However, the study of psychical mechanisms and the relevant so-called pathologies need to be connected to a lot of theoretical (and clinical) disputes about the relations of the psychic to the social (and surely Lacan's and Deleuze's approaches are different). This becomes crucial because Casey seems to indeed offer interesting suggestions: Could expressive gestures support links of the split self to the world it has lost? Could the awareness of edge psychic phenomena be part of healing processes? Replacing borders between the split self and the world with "lively and permeable" boundaries (258) may possibly hint towards a becoming of a rich and open self.

It seems that Casey has developed a very interesting argument with many levels of implications to a rethinking of the self and the experiences of space and time. One of his major contributions is to help us think in concrete terms about how an important spatio-temporal experience, the experience of edges, may become the means to understand crucial aspects of the being-in-the world. In a different theoretical context, his discussion could have unfolded as a discussion of edge-as-a-metaphor. And indeed, this huge capacity of humans to connect and interpret parts of their experience and thoughts through analogies they establish between 
different realms of life seems to be at the center of thinking through edges. Or at the center of thinking at the edge. And this capacity may even help us rethink about our world which is being perilously drawn to an edge... 


\section{Antonis Vradis on Edges, Common Spaces and Spatial Contracts}

For those of us caught in the hustle and bustle of UK academia, sitting down to read each other's work and to have a genuine conversation about it seems like an out-of-reach luxury. Let this sink in for a second: what should be one of the prime features and cornerstones of our work has been lost somewhere along the gazillion hurdles thrown at us, by never-ending targets, always edging past and above the feasible; administrative overburdening, mass teaching and marking; in short: work overload all over. This, of course, for those-by now in the minority-fortunate enough not to have to constantly seek out their next gig, those who don't have to keep on applying just to stay in the game. The situation, it would seem, is not at all different in other parts of the (greater) global West. And so it is both an immense pleasure and a real privilege to enter into conversation with Ed Casey and Stavros Stavrides. This conversation is additionally important, if I may say so, for another reason: it comes at a moment when for all the talk of international solidarities and common(ing) struggles, and for all our pride of being in a field particularly open to cross-border intellectual exchanges, there does not appear to be as much, essentially, going on. Better, perhaps: there is not enough to counter the populist, farright wave, to hold back reactionary enclosures raised the world over, shattering and breaking it apart.

I wish to begin my own response to Stavros and Ed's reflections with one observation stemming from the above, one which has concerned me greatly, and is an essential reason why I thought this exchange was timely, right now. The observation is that we do indeed feel-we are told so-that we live in a world that is constantly on edge. Whether running after our next work contract (see above), anguishly awaiting the outcome of yet another summit, another negotiation, another peripheral, physical, trade or discursive war, the fact remains the same: we are being put on, and directed to squarely remain on edge. And this edginess is something that violently clouds our vision and thinking. Take the effect of our always-on culture, our constant online presence that leaves no space for one to wander, to think in a way that is unforced and free-flowing, to process information and data in any pace or scale fitting for the human mind-not some exponentially fast computer processor. Or look at the barrage of information we are subjected with daily and by the hour even. One pending-or playing out already - catastrophe after another, curtailing further the ever-shrinking mental space in which one can soberly reflect and think before acting upon. The world on edge indeed: a time of doom, whether this might be the small, personal loss of life or the major and the mass-scale: from "an impersonal elsewhere against which we feel ourselves defenseless" (Casey 2017: 346) down to the most private, individual and extremely personal. So yes, there is doom all around, from the intimate to the global. But here is a question: once we accept that doom is all around us, right now, at the present moment, why aren't we considering whether this had always been the case? Even "when not perilous, life is uncertain, always precarious to some degree" (Casey 2017: 341). Always precarious. Not just individual life, but social, too: has there not been, throughout history and the world over, a great degree-equivalent, if not greater than the present-of pain, insecurity and suffering? Has humanity not always lived on edge? My own humble answer is, not quite. Even though suffering had always been there to a great degree-obviously-there are at least three novel features of our current "suffering moment" that set it apart.

First is the sheer degree of suffering and destruction. There are certain elements of our present doom moment (perhaps most notably: climate change and the always-impending nuclear threat) that are historically unprecedented; they are novel and unique to our present. Never before has humanity teetered on the brink of collapse and extinction in this way. But at the same time, there are other elements of our doom moment that are, unfortunately, far from unique. Think of the global financial crisis, or the threat of yet another world war: humanity's history is written on a long warpath; and economic crises are essentially the revitalising "reset button" of capitalism. Sadly but most definitely, neither make an appearance for the first time. 
Second, this is the first time in over half a century that us, the fortunate few populating the Global West (both its core and fringes) feel there is something amiss in the discourse of endless prosperity and stability we were lured with this far: the horrors of WWII were meant to be behind us, wars (in the capitalist core alone, of course) were also supposed to be a thing of the past. States were expected to act, to one degree or another, as facilitators of not-entirelyuneven distribution of wealth, and to cast a safety net for those not fortunate enough: welfare state, state regulation (but not-too-heavy intervention, remember) of the market, and the longest time without a war on European and North American soil. The triptych of liberal democracy, welfare regimes and industrial capitalism seemed to work well and long enough. This was truly the time of outsourcing: the western system of order outsourced its wars to peripheral and proxy lands, at the same time also outsourcing the cheapest and most cumbersome of its production needs to these very peripheries, keeping for the core little other than management and consumption: the management and consumption of wars and of products alike. The first cracks in this "outsource capitalism" appeared in the early 2000s, when 9/11 and the alter-globalisation riots made it evident that such clear-cut spatial segregation (production/consumption; centre/periphery war/peace) was not meant to hold much longer. Fast-forward to 2018, and populist demagogues are running the show pretty much across the board, from the capitalist core all the way out to its fringes. Lines are hastily redrawn, and convenient scapegoats have willing fingers pointed at them once again. But similarities with our recent historical past end here, for the time being. Instead of the crude force of occupation, and all-out war, these rising totalitarian powers have an arsenal of technologies by which to register, monitor and ultimately control the flow of information and people alike. A techno-industrial complex that both includes but exceeds the military-industrial complex.

And just to add a tad more to this gloomy picture, there is a third element in our present moment that sets it even further historically apart. This third element is of course how we now find out all about the news. The astronomical rise of the internet and social media, now dominating our lives in previously unimaginable ways, inadvertently or directly leading to all sorts of surreal outcomes, from the rise of a racist clown to what is (was?) arguably the most powerful office in the world, to the most personal and intuitive: with this, and with the social media facilitating a simultaneous and persistent attack on our individual, personal boundaries, one would think we have now reached a point of no return. By this point, returning to the previously established status quo might be less conceivable as a model of future governance than, say, the United States being run by a racist hologram in the next decade; or that citizenship will no longer be granted either through blood or soil, but will instead be constantly dependent upon an ever-enhanced and up-to-date online profile.

This is all quite ludicrous and far-fetched, but not more so than what the current situation would have seemed in the eyes of most of us, only a decade a go. And so we are witness and subject to a tripartite transformation: first, a transformation of our physical surroundings: natural catastrophes of unprecedented scale. Second, a transformation of the social status quo, unprecedented in relative historical terms: yes, we have seen this sort of power excess before in the Global West, sure-but not since the end of WWII. And third is the sheer speed at which news over these transformations is now relayed. This is significant: the way in which information flows determines so much about the actual state of our world. Let us conduct a brief mental exercise for a second: what would have WWII been like if social media was around at the time? What strategic ambushes would have leaked, what collaborators would have been outed (real or not), how could have humanity ever deny knowing about the Camps?

Our physical environment is being transformed, as is our social-a dual reason why the way in which populations are managed can and must change in return; and there is now the technological capacity to push through with these changes as well. We are ushered into an era when resources are even more unevenly, yet precisely distributed. We are in this way swiftly moving away from the-relative-universality of the social contract, and into the highly 
individualised, customisable and ever-retractable spatial contract; what I have previously described as a spatially dependent and confined invocation and granting of rights previously invoked and granted at the national, if not the international level. In other words: the social contract in its recognisable universality is no more. What replaces it is a highly spatially defined and dependent distribution of ever-invocable rights. From the "postcode lottery" of accessing decent education or healthcare in the UK, all the way to the homeless camps barely tolerated in strictly delineated quarters ("skid rows") of otherwise illustrious downtown areas, bordering the Central Business Districts of major US cities; to the strict confinement and containment of dissent in a 'riotous neighbourhood' in Athens; and to the concentration of cheap and surplus workforce in dense and contained informal housing zones in the semi-peripheries of megacities across the global semi-periphery: the invisible thread connecting these otherwise disparate cases is the unmistakably spatial management of populations by the powers-that-be.

This is why Stavrides strikes such a chord when he calls for worlds of commoning against the world of enclaves enforced upon us by capital today. There is, as Casey points out in his own review, an intriguing divergence between the two when it comes to their understanding of the border, which can be porous for Stavrides $(2016$ : 54, 65) and essentially impermeable for Casey (2018: 7-38). I find this seeming divergence most intriguing, not least because in the essence of their arguments, Stavrides and Casey very much converge on the need to distinguish between 'hard' and 'impermeable' lines that divide, and the 'porous' and 'traversable' lines that facilitate exchange and commoning. Both books and the terminology they propose pave the way for a dictionary of the various new spatial contracts as these are taking shape today. Contracts in plural, because the universality of the social contract is giving way to highly individualised and spatially-bound relationships between authorities and populations. Rights are confined into space, rendering them compartmentable, intransferable and essentially powerless. The question is whether and how we can build an epistemological vocabulary that speaks of, to and against this compartmentalisation of rights-in-space.

As Stavridis notes, Casey is building some solid foundations of such, analysing terms that can help us in this direction (folds, creases, margins, verges and so on) and in discussing place as distinct from space; the lived experience of the former helping make edges alive and connecting nodes, as opposed to the lethal divisions of the border. Similarly, Casey convincingly argues that just like place holds the lived experience advantage over space, the "event" is also similarly lived and experienced as opposed to time. Any of us who have lived through key events (the Grigoropoulos uprising of 2008 or the anti-austerity protests of more recent years are good examples of such here in Greece) can most definitely relate to this. Now, at the moment when power dictates our movement in space, engulfing more and more of us into enclaves, and as it also presides over time, ruling through the emergency, this new epistemological vocabulary is essential. I would like to humbly suggest that the notion of a "spatial contract" might be able to help in this direction, serving at least three purposes: one, it helps break away from an otherwise simplistic dichotomy where power alone dictates the rules of the game. Much like Stavrides' "commoning" it denotes a process, which is reflected by, but does not culminate in the establishing of a contract. Second, it reflects the certain degree of agency the contract's subjects have: however unequal the relationship, this is still present; power continues to rely on the existence of subjects in order to affirm its authority, and it continues to need some level of consensus to assert its moral authority. And third, the notion of contracts, in plural, reflects the multiple but still individual reality each of us is now faced with, a tailor-made, individualised relationships to authorities that is ever-subject to change. Much like capital took the demand for labour flexibility and mobility and twisted them into precarity and forced migration, there is also a risk with commoning as a process that contrasts with capitalist enclosures and "enclaves". After all, at the forefront of capitalist transformation is a fluid, eversubject to change condition of uncertainty, an expanding unbecoming of all that constituted our relationship to the powers-that-be. The stake-at-hand is no less than finding a way to transform 
the common worlds of the past into inclusive and ever-expanding places away from the influence of capitalist domination. At a time when the language and the actions of capitalist domination also point at a blurring of boundaries and an ever-conditional, ever-shifting present, words matter more than ever. For this reason, once again, this interaction with the words and works of Ed and Stavros has been invaluable, and might hopefully serve as the smallest of contributions in comprehending and then struggling against the compartmentalisation of our rights and livelihoods in ever-shrinking, ever-conditional enclaves; a humble contribution in the process of undrawing these violent, divisive and lethal lines. 